\title{
El ethos económico como factor de legitimación del ordenamiento jurídico colombiano
}

\author{
DAVID ALFARO PATRÓN \\ NELSON HERNÁNDEZ MEZA \\ ADELAIDA IBARRA PADILLA, \\ GEANCARLO MEJÍA NIETO
}

Fecha de recepción: 30-06-09 - Aprobación: 01-08-09

\section{Resumen}

La estructura social colombiana tiene formas de vida tan diversas como regiones y culturas hay a lo largo y ancho de la geografía nacional, lo cual conlleva a que no exista un concepto unívoco de bien común que determine la legitimidad del ordenamiento jurídico nacional. Se observa entonces que el factor económico es el que legitima el Derecho colombiano en la medida en que la producción normativa responde a los intereses de los grupos que manejan el ethos económico, lo cual evidencia que la legitimidad de nuestro Derecho no radica en el conjunto de costumbres, valores, tradiciones, símbolos y hábitos que definen la identidad de nuestros nacionales, sino en el factor económico y en los intereses de los grupos sociales que lo detentan.

\section{Palabras claves}

Legitimidad, eticidad, ethos dominante, consenso, minorías.

\section{Introducción}

El presente documento intenta presentar unos argumentos de carácter propositivos que sirvan para justificar el planteamiento consistente en que la legitimidad del ordenamiento jurídico en Colombia radica en el ethos económico, a partir del supuesto de que la estructura social colombiana está constituida por formas de vida tan diversas como regiones y dialectos hay a lo largo y ancho de la geografía

\section{Abstract}

The Colombian social structure is composed by as many different lifestyles as many are the regions and cultures on the national territory. This complexity results in the fact that it does not exist a univocal concept of common good that is able to determine the legitimacy of the national juridical order. It is anyhow clear that the element with the strongest influence is the economical one, as far as the production of laws corresponds to the interests of the economical leading group. Therefore the legitimacy of our juridical order is not based on the customs, values, traditions and habits that are the identity of our nation, but on the economical factor and on the interests of the leading social groups.

\section{Keywords}

Legitimacy, ethicity, dominant ethos, consensus, minority. nacional, lo cual trae como consecuencia que no exista un concepto unívoco de bien común que determine en dónde radica la legitimidad del ordenamiento jurídico nacional. Por tanto, tiene como efecto directo para el ámbito de la creación de las normas jurídicas, que la legitimidad de estas sea la manifestación de un único ethos, el dominante, que puede ser el que detenta el poder económico, que a su vez depende del complejo entramado economía-política-religión-ciencia y que se encuentra representado en la figura del presidente 
de la República, es decir, la existencia de un Derecho estructurado ya no por una legitimidad legal racional sino por una legitimidad carismática (Farinas, 1991), según lo acreditan los hechos que ocurren en nuestra realidad nacional.

En esta medida, entonces, resulta de particular interés estudiar la problemática del concepto de legitimidad e identificar qué es lo que legitima el Derecho en Colombia, y establecer si la hipótesis planteada es válida en nuestro contexto social actual. Para ello se parte de Rawls, siguiendo con los autores liberales, comunitaristas y marxistas, hasta llegar a Habermas, en la búsqueda de justificar o darle respuesta al planteamiento formulado.

\section{DAVID ALFARO PATRÓN}

Abogado de la Universidad de Cartagena. Especialista en Derecho Comercial de la Universidad del Norte. Candidato a magíster en Derecho de la Universidad del Norte. da-alfaro@hotmail.com

\section{NELSON HERNÁNDEZ MEZA}

Abogado de la Universidad del Norte. Candidato a magíster en Derecho de la Universidad del Norte. Profesor de las asignaturas de Introducción al Derecho I y II en la Universidad Autónoma del Caribe.

n_hernandez_meza@yahoo.com

\section{ADELAIDA IBARRA PADILLA}

Abogada de la Universidad del Atlántico. Candidata a magíster en Derecho de la Universidad del Norte. Candidata a magíster en Gestión Sostenible de la Universidad Leuphana Lüneburg. Docente catedrática de la asignatura Constitución y Democracia en la Universidad Autónoma del Caribe.

halloadela@hotmail.com

\section{GEANCARLO MEJÍA NIETO}

Abogado de la Universidad Libre de Barranquilla. Especialista en Derecho contencioso administrativo de la Universidad Externado de Colombia. Candidato a magíster en Derecho de la Universidad del Norte. Profesor de la asignatura de Práctica Forense en las Universidad del Norte y Libre de Barranquilla. gmejia11@gmail.com

\section{Planteamiento del problema}

Si se toma como punto de partida el supuesto de que la legitimidad del Derecho de un país radica en el acuerdo de las mayorías, en términos kantianos, y en el acuerdo con base en mínimos, en términos rawlsianos, y de advertir la imposibilidad de tales presupuestos, se establece que de ser así, entonces ninguno de los ordenamientos jurídicos sería legítimo, ya que no responden a un consenso y, sin embargo, son capaces de mantener cohesionada a la sociedad. Por esta razón se esboza la idea del factor económico como elemento de legitimación del Derecho a luz de otros autores como Habermas, Foucault y Marcuse.

Hemos de analizar la fuente de legitimidad del ordenamiento jurídico colombiano partiendo del hecho de que la Constitución colombiana no obedece a un consenso sino a acuerdos establecidos entre los constituyentes, personas morales que representaron los intereses, principios y bienes sociales primarios propios de un sector de la sociedad; en otras palabras, que personifican un ethos, que colisiona con otros que le son antagónicos, en una perenne lucha por lograr imponerse. De forma tal, que la legitimidad de la norma fundamental no puede provenir del consenso al modo rawlsiano, porque este supone un velo de ignorancia, lo cual es fácticamente imposible porque desconoce la multiculturalidad de la cual no logran ni pretenden desprenderse los constituyentes.

Bajo esta consideración, se comprende que la legitimidad de nuestro Derecho deviene de la capacidad que tenga un ethos para imponerse sobre otro, manteniendo la estabilidad jurídico-política del Estado, en el entendido de que el contrato constitucional es fruto del acuerdo entre los más fuertes y del equilibrio de fuerzas entre los grandes vencedores de la sociedad, ganadores en la pugna de la economía de mercado, determinada por unas reglas espontáneas establecidas en la sociedad. De modo que la legitimidad de nuestra normatividad se adquiere compitiendo y la eticidad más fuerte en la economía es la que se impone sobre la más débil.

\section{Aproximaciones a los conceptos de le- gitimidad y eticidad como fundamentos de los sistemas jurídicos}

La controversia acerca de dónde radica la legitimidad del Derecho data de mucho tiempo atrás. El debate surge en la Grecia antigua entre Platón y Aristóteles. Para el primero, la idea del bien es supuesta, esto quiere decir que parte de la concepción de que el bien tiene un mismo significado para todos; Aristóteles, por su parte, la problematiza (Hegel, 1980).

En el libro La política, Aristóteles (1984) plantea que el bien es el bien común y a este lo define la politeia, 
aunque, no obstante, su contenido lo determina la ética. El ethos es entendido, entonces, como un conjunto de costumbres, valores, tradiciones, símbolos y hábitos que definen la identidad de un colectivo. Aristóteles (1985: 1131) basa la ética en las virtudes de las cuales se deriva el concepto de justicia.

En la Edad Media, la consideración del pueblo como titular o sujeto primario del poder político legítimo, recibido en último término de Dios, tiene en Tomás de Aquino más que ver con la noción del bien común, como finalidad del poder, que con la democracia como forma de ejercicio, aunque deja un cierto papel al consenso popular, siempre mediado y dirigido por los estamentos superiores, la nobleza, el alto clero y, quizá, algunos ciudadanos notables, esto es, los más ricos burgueses o habitantes de los burgos o ciudades medievales.

Luego, Hobbes (1989: 144), contractualista, precursor del iusnaturalismo moderno, aborda el conflicto del consenso y la legitimación externa del Derecho. Para él,

el único modo de erigir un poder común que pueda defender a los hombres de la invasión de extraños y de la injurias entre ellos mismos (...) es el de conferir todo su poder y toda su fuerza individuales a un solo hombre o a una asamblea de hombres que, mediante una pluralidad de votos, puedan reducir las voluntades de los súbditos a una sola voluntad $(\cdots)$. De este modo se genera ese gran Leviatán, ese dios mortal a quien debemos, bajo el Dios inmortal, nuestra paz y seguridad.

Hobbes (1984: 266) introduce por primera vez el concepto de equidad, trata el problema de la obediencia al Derecho y reconoce el Derecho a la resistencia. En este punto expresa que "quien no pueda ser castigado legalmente, tampoco puede ser resistido legalmente".

Por su parte, Locke (1991: 131) entiende la sociedad como una renuncia de los hombres a la igualdad, la libertad y al poder ejecutivo que tenían en el estado de naturaleza, para que el poder legislativo disponga de ello, pero con una limitante: "según lo requiera el bien de la sociedad, esa renuncia es hecha por cada uno con la exclusiva intención de preservarse a sí mismo y de preservar su libertad y su propiedad de una manera mejor".

Después, para Rousseau (1969: 360), liberal republicano, la ley es la voluntad de la colectividad; el fundamento de la legitimidad política queda subsumido en democracia directa procedimental: encontrar una forma de asociación que defienda y proteja con toda la fuerza común a la persona y los bienes de cada asociado y por la cual cada uno, al unirse a los demás, no se obedezca sin embargo más que a sí mismo y permanezca tan libre como antes.

Así mismo, Rousseau (1969: 371) afirma que "si cuando, suficientemente informado, el pueblo delibera, los ciudadanos no tuvieran ninguna deliberación entre sí, del gran numero de pequeñas diferencias resultaría siempre la voluntad general y la deliberación sería siempre buena".

Con posterioridad, Kant (1958: 43), al tratar el tema del hombre en sociedad, nos habla de insociable sociabilidad de los hombres y nos explica este antagonismo en el hecho de que:

El hombre tiene propensión a socializarse, porque en este estado siente más su condición de hombre; es decir, tiene sentimiento a desarrollar sus disposiciones de naturaleza. Pero también posee una gran inclinación a individualizarse (aislarse), porque al mismo tiempo, encuentra en él la cualidad insociable de querer dirigir todo simplemente según su modo de pensar (Sinne).

También para Kant, el Estado es la máxima expresión de la eticidad, que se caracteriza por la ausencia de contenido moral y su función es interpretar y preservar el ethos del cual deviene a través de la dimensión política y jurídica. Kant entiende el principio de la autonomía como "elegir de tal manera que las máximas de la elección del querer mismo sean incluidas al mismo tiempo como leyes universales" (2003: 97).

Hegel, a su vez, enseña, que el Derecho será válido y la política legítima, en la medida en que la eticidad, por medio del Estado, respete la protoforma del ethos y la identidad de las comunidades; la eficacia del ordenamiento queda, igualmente, sujeta a esa traducción jurídico política que el Estado hace de la identidad ética de un pueblo (Mejía, 2006a).

Para Weber existen tres clases de poderes: el poder legal, cuya legitimidad se basa en la creencia en la legalidad de las normas del régimen, instituidas deliberadamente y de modo racional, y del derecho a mandar de quienes detentan el poder basados en tales normas; el poder tradicional, que se apoya en el respeto a las instituciones consagradas por la tradición y a la persona que detenta el poder, cuyo derecho de mando se atribuye a la tradición; y el poder personal o carismático, cuya legitimidad se funda sustancialmente en las cualidades personales del jefe y, en forma subordinada, en las instituciones (Mejía, 2006b).a 
Respecto al proceso de racionalización occidental, descrito por Weber, el profesor Mejía Quintana expresa que este se caracterizó históricamente por dos factores que originan el inicio de la desaparición de la sociedad tradicional.

En primer lugar, se produjo un desencantamiento de las cosmovisiones tradicionales del mundo, o racionalización de las imágenes del mundo, con el cual las antiguas imágenes cosmológicas (religiosas, metafísicas, sociopolíticas, estéticas) sufrieron un proceso de sistematización y progresivo horadamiento, perdiendo el poder vinculante cohesionador que tuvieron en las sociedades tradicionales premodernas. La ética religiosa se vio reemplazada por un punto de vista moral profano (...) Este proceso de racionalización cultural tiene como consecuencia el surgimiento de un tipo de acción social, caracterizado por una acción racional con arreglo a fines, propia de la sociedad capitalista (Mejía Quintana, 2006b: 202).

En el año 1934, Hans Kelsen publica su obra Teoría pura del Derecho, en la cual plantea que la validez del Derecho reposa en la denominada norma fundamental o Grundnorm, la cual se caracteriza por ser pre supuesta, no pensada, no fundamentada y, sobre todo, carente de contenido material, lo que hacía autónomo al Derecho,. Las condiciones de validez no se hallan en lo moral o eficacia de la misma. Su legitimidad está amarrada a la procedimentalidad; para Kelsen, justicia es procedimiento (Mejía, 2006b).

Luego, Schmitt (1971) afirma que la forma de legitimación más corriente hoy es la fe en la legalidad. En relación con el concepto de igualdad y el uso del poder por parte de quien lo ostenta, Schmitt afirma que

puede contener una conciencia de pertenencia que les está conferida de manera especial a los miembros de la minoría dominante. Pero no existe ningún fundamento racional para suponer que este sentimiento -aún cuando exista en los poderes que poseen derechos dictatoriales- pueda motivarlos para que actúen en interés de los dominados (Kaufmann, 1993: 106).

Para Schmitt (1991: 75) el aporte de un Estado consiste en procurar en su territorio "paz, seguridad y orden” y crear así la situación normal que constituye el presupuesto necesario para que las normas jurídicas puedan tener vigencia en general, y agrega: "Estado como unidad política, mientras exista como tal, está capacitado para determinar por sí mismo también al enemigo interno".
Austin, por su parte, expresa que las sociedades reales, no son lo suficientemente ilustradas y la obediencia que sus miembros prestan habitualmente al soberano tiene como causas la costumbre o los perjuicios, y agrega, además, que en estas sociedades la obediencia se funda en una razón utilitarista: la percepción de la conveniencia del gobierno político en contraposición con la anarquía (Turegano, 2001: 461).

Hart, posteriormente, define un tipo de norma fundamental empírica denominada regla de reconocimiento, que "contiene los criterios para la identificación de reglas o normas como Derecho válido, pero también contiene los criterios y las razones de validez de todas las demás reglas, tratándose siempre de reglas empíricas" (Mejía, 2006b).

Hart (1963: 137) entiende la regla de reconocimiento "como una práctica compleja, pero normalmente concordante, de los tribunales, funcionarios y particulares al identificar el Derecho por referencia a ciertos criterios. Su existencia es una cuestión de hecho".

Por otra parte, Luhmann en su Racionalidad sistémica, nos habla de que el sistema jurídico es un constructor de operaciones jurídicas: produce y ordena relaciones; es red comunicacional de circuitos autorreferenciados.

El Derecho deviene del procedimiento puro y aunque es un subsistema más del macro-sistema, de él dependen gran parte de los procesos funcionales que garantizan la autoadaptación del sistema a su complejidad creciente, a través de procedimientos jurídicos despersonalizados que aseguren tal objetivo (Mejía, 1995).

Para Luhmann (1997: 14), un sistema complejo es aquel que "incluye tantos elementos, que ya no puede ser combinando cada elemento con cada uno de los otros, sino que las relaciones deben producirse selectivamente".

La complejidad social se reduce constriñendo la complejidad interna del sistema jurídico. El Derecho reduce complejidad social en términos de validez jurídica, no de eficiencia social o legitimidad política (Mejía, 2006a).

Por su lado, Teubner (2002) define el Derecho como un sistema social autopoiético, esto es, como una red de operaciones elementales que recursivamente reproduce operaciones elementales, donde los elementos básicos de este sistema son comunicaciones y no normas.

Dichas comunicaciones están interrelacionadas entre sí en una red de comunicaciones que no produce otra cosa que comunicaciones. Esto es autopoiesis: La auto-reproducción 
de una red de operaciones comunicativas mediante la aplicación recursiva de comunicaciones a los resultados de comunicaciones anteriores.

Por otra parte, Bourdieu (2002: 161) sostiene que El Derecho registra en cada momento un estado de relación de fuerzas y ratifica con ello las conquistas de los dominadores, que quedan convertidas de esa forma en acervos reconocidos.

La concepción de la justicia que Rawls se propone explicar es la de la justicia como equidad, una noción pública de la justicia propia de una sociedad bien ordenada. Lo que significa encontrar unos principios defendibles por un conjunto de seres racionales en una situación de igualdad inicial, ya que solo desde la igualdad esos seres serán capaces de ponerse de acuerdo y decidir imparcialmente. Y es la imparcialidad, equidad o fairness, lo que define propiamente la justicia.

Para conseguir las condiciones de igualdad deseada será preciso hacer abstracciones de la sociedades imperfectas y desordenadas en que vivimos e idear un "estado originario" en el que se den los requisitos para elegir desinteresadamente. Esta situación originaria ideal reproduce, en términos contemporáneos, el llamado "estado de naturaleza" de las viejas teorías del contrato social, en el cual no existan diferencias fundamentales cuyo peso sea un obstáculo para la limpia decisión de los seres que intervengan en el acuerdo.

A esa situación la llama Rawls (1990) "posición originaria” y está caracterizada porque los seres que concurren en ella se encuentran cubiertos por un "velo de ignorancia". De igual modo, ese velo de la ignorancia significa que los individuos en cuestión desconocen todos aquellos aspectos y contingencias de su existencia, tales como su clase o estatus social, sus dotes o habilidades naturales, su fuerza e inteligencia. Conocen únicamente algo tan vago e impreciso como "los bienes generales de la naturaleza humana". Los individuos -que "son racionales"tomarán una decisión y llegarán a un acuerdo sobre el tipo de sociedad en la que quieren vivir. La teoría de la justicia aparece como una parte significativa de la teoría de la decisión racional.

Nozick (1990: 189), al analizar el autor en comento, sostiene que:

Rawls imagina individuos racionales, mutuamente desinteresados, que se encuentran en cierta situación o apartados de sus otras características no proporcionadas por esta situación. En esta situación hipotética de opción, la cual llama Rawls "la posición original", ellos escogen los primeros principios de una concepción de justicia que debe regular todas las siguientes críticas y reformas de sus instituciones.

La perspectiva expuesta permite a Rawls formular los dos principios fundamentales de la justicia, aquellos que, a su juicio, escogerían inevitablemente los seres que concurren a la posición original. Son los siguientes: (a) Toda persona tiene derecho a un régimen pleno de libertades básicas iguales, que sea compatible con un régimen similar de libertades para todos. (b) Las desigualdades sociales y económicas, han de satisfacer dos condiciones. Primera, deben estar asociados a cargos y posiciones abiertos a todos en las condiciones de equitativa igualdad de oportunidades y, segunda, deben procurar el máximo beneficio de los miembros menos aventajados en la sociedad.

En resumen, dos principios de hecho, se desdoblan en tres: (a) el principio de la libertad; (b) el de la igualdad de las oportunidades y (c) el llamado "principio de la diferencia”, que ordena beneficiar a los miembros de la sociedad menos favorecidos... y consiste en que una distribución determinada es suficiente cuando no es posible cambiarla sin mejorar a determinadas personas, sin empeorar, al mismo tiempo, la situación de las demás.

Rawls, según interpreta Nozick (1990: 188), sostiene que "las desigualdades se justifican si sirven para mejorar la posición del grupo que se encuentra en peor condición en la sociedad; sin las desigualdades, el grupo en peor condición estaría aún peor".

En resumen, el contexto sobre el cual entreteje el concepto la posición original, con la cual los individuos deben entrar a participar para establecer el consenso de los mínimos, debe entenderse como un mecanismo de representación en el que se modelen nuestras convicciones razonadas como personas razonables describiendo a las partes (cada una de las cuales es responsable de los intereses fundamentales de un ciudadano libre e igual) en una situación equitativa desde la que alcanzan un acuerdo sujeto a restricciones adecuadas sobre las razones que respaldan los principios de la justicia política (Rawls, 2001: 43).

Los principios de la justicia se escogen tras un velo de ignorancia. Esto asegura que los resultados del azar natural o de las contingencias de las circunstancias sociales no darán a nadie ventajas ni desventajas al escoger los 
principios. Dado que todos están situados de manera semejante y que ninguno es capaz de delinear principios que favorezcan su condición particular, los principios de la justicia serán el resultado de un acuerdo o de un convenio justo (Nozick, 1990: 189).

Buchanan (1996: 37), al referirse a la ética del trabajo, afirma que "es claramente posible que en algunas circunstancias las restricciones éticas puedan devenir excesivamente severas y actuar en el sentido de reducir en vez de incrementar el bienestar individual".

Adorno (1969: 218), por su parte, sostiene:

Ninguna sociedad que contradiga su propio concepto -el concepto de humanidad- puede poseer plena conciencia de sí mismo. Para impedírselo no hace no siquiera falta la actividad subjetiva de la ideología, aunque, en tiempos de cambio histórico importante, ésta suele reforzar y adensar la ceguera. Peor el hecho de que as diversas formas de represión -según el estadio de la técnica en cada caso- se pongan al servicio de la conservación del conjunto social, y el hecho de que la sociedad, pese a todo el absurdo de su modo de ser, reproduzca la vida en las circunstancias dadas, suministran una apariencia de legitimación.

Alasdair Macintyre (2001: 134), comunitarista, argumenta que el proyecto ilustrado de Kannt fracasó, y no cree que el mundo se rija por los principios universales sino por los valores concretos, los cuales están representados en la eticidad de un colectivo:

El individuo comienza por identificar su bien individual y preguntarse por los medios que debe emplear para conseguirlos; pero pronto descubre que si no coopera con los demás, tomando en cuenta que también aspiran a alcanzar sus respectivos bienes individuales, los conflictos resultantes serán tales que harán imposible que alcance su propio bien, salvo muy a corto plazo y a menudo ni siquiera eso. De modo que tanto él como los demás encuentran en cierto tipo de cooperación un bien común que es un medio para que cada cual consiga su bien individual, y que se define en término de los bienes individuales.

Taylor (2002: 121), comunitarista, en referencia a la autenticidad, sostiene que han de evitarse dos posiciones simples y extremas, la de partidarios y la de detractores, respectivamente; y que la condena de raíz de la ética de la autorrealización supone un profundo error, como lo supone la completa aprobación pura y simple de todas sus formas contemporáneas. Asimismo, sostiene que: se producen tensiones entre los ideales éticos subyacentes y las formas en que llegan a reflejarse en las vidas de las personas, lo que viene a significar que el pesimismo cultural sistemático anda tan errado, como el optimismo cultural global. Por el contrario, nos enfrentamos a una lucha continúa por realizar formas de autenticidad más elevadas y plenas contra la resistencia de formas más chatas y superficiales.

De otro lado, Alexy (2001: 95), al hablar de la fundamentación de los derechos humanos, y en especial de lo que legitima las reglas que regulan los comportamientos sociales, señala que las decisiones deben tomarse de acuerdo con procedimientos reglados jurídicamente, por ejemplo, sobre la base del principio de mayorías.

El problema de la ejecución surge porque el conocimiento de la corrección o legitimidad de una norma es algo distinto a su cumplimiento. Del hecho que en discursos puedan elaborarse juicios, pero no siempre las correspondientes motivaciones, se deduce la necesidad de reglas revestidas de coactividad y con ello la necesidad del Derecho.

Ahora Alexy (2001: 96) afirma que el problema de la organización de los individuos no puede alcanzarse mediante acciones individuales o de cooperación espontánea, pues la racionalización requerida presupone al Derecho. La renuncia a las instituciones sociales en forma de Derecho, fundada en otro tipo de argumentos sería anarquía.

"Para Marx (1989: 380), la racionalización se impone directamente en el despliegue de las fuerzas productiva; es decir, en la ampliación del saber empírico, las mejoras de las técnicas de producción y en una movilización, cualificación y organización cada vez más eficaces de la fuerza de trabajo socialmente utilizable. Por el contrario, las relaciones de producción; es decir, las instituciones que expresan la distribución del poder social y regulan el acceso diferenciado a los medios de producción, solo pueden revolucionarse en merced a la presión racionalizadora que ejercen las fuerzas productivas". (Habermas, 1989:380).

Ernst Bloch (1983: 236) sostiene:

la consecuencia para los peor librados de la sociedad capitalista, es el destino de poder ser renovadamente una mercancía invendible por sí misma, la simple mercancía de la fuerza del trabajo. Ello conduce a una tal autoalienación de todos los explotados y convertidos en mercancía bajo los explotadores, a tal esterilidad del ser humano, a tal alienación, que permanente presiona y paraliza. Y esto únicamente en razón del salario de esta fracción de la plusvalía que fluye a los trabajadores 
y empleados, plusvalía que ellos han producido y salario que únicamente tiene que servir para la reproducción de la fuerza de trabajo del próximo día; con lo que se cierra siempre de nuevo el paralizante círculo del trabajo.

Marcuse (1968: 15), por su parte, en relación con la concepción totalitaria del Estado, señala que este se caracteriza por las siguientes contraposiciones:

la sangre contra la razón formal, la raza contra el finalismo racional, el honor contra la utilidad, el orden contra la arbitrariedad disfrazada de libertad, la totalidad orgánica contra la disolución individualista, el espíritu guerrero contra la seguridad burguesa, la política contra el primado de la economía, el estado contra la sociedad, el pueblo contra el individuo y la masa.

Con respecto a los modelos normativos de democracia, Habermas (1999: 231) expresa:

según la concepción liberal, el Estado se concibe como el aparato de la administración pública y la sociedad como el sistema de interrelación entre las personas privadas y su trabajo social estructurado en términos de la economía de mercado.

De acuerdo con la concepción republicana, la política se concibe como una forma de reflexión de un entramado de vida ético. Constituye el medio con el que los miembros de las comunidades en cierto sentido solidarias asumen su reciproca dependencia y con el que en su calidad de ciudadanos prosiguen y configuran con voluntad y conciencia las relaciones de reconocimiento recíproco con las que se encuentran convirtiéndolas en una asociación de miembros libres e iguales.

Diego Farrell (1997: 99) define el gobierno democrático como

la alternativa que cuenta con el apoyo de la mayoría es la alternativa elegida. La mayoría entonces, puede optar por leyes que repriman a una minoría racial o religiosa, aunque el caso que más le preocupa a Mill es el de una mayoría pobre que viola los Derechos de propiedad de una minoría rica.

\section{Fundamentos epistemológicos para sostener que el factor económico es un instrumento de legitimación de los sis- temas jurídicos}

Para sustentar que los intereses económicos de ciertos grupos sociales son los que determinan la legitimidad de los sistemas jurídicos, es necesario retomar a Kelsen (1969: 219) cuando afirma:

el enfoque sociológico del problema del Estado, procede de la suposición de que los individuos que pertenecen a una misma comunidad política están unidos por una voluntad común o, lo que equivale a lo mismo, por un interés común. Hablase de una voluntad colectiva o de un interés colectivo, y se piensa que estos constituyen la unidad y, por tanto, la realidad social del estado. Se habla así mismo, de un sentimiento colectivo, de una conciencia colectiva, especie de alma colectiva, como del hecho que constituye la comunidad del Estado.

Coincidimos con Kelsen (1969: 220) cuando expresa:

en realidad, la población de un estado hallase dividida en varios grupos de intereses que en mayor o menor escala se contraponen entre sí.

La ideología de un interés estatal colectivo es empleada para encubrir ese inevitable conjunto de intereses. Llamar interés de todos al expresado en el orden jurídico, es una ficción, inclusive cuando ese orden representa un compromiso entre los intereses de los grupos mas importantes. Si el orden jurídico fuese realmente la expresión de los intereses de todos, entonces podría contar con la obediencia voluntaria de todos sus súbditos; no necesitaría tener carácter coercitivo.

Ahora, para Rawls (1990: 73), los principios asequibles a las partes en la posición original deben estar reconociblemente ligados a la concepción de los ciudadanos como personas libres e iguales. Estos principios, como principios de la estructura básica de la sociedad, deben contener una noción de reciprocidad apropiada a los ciudadanos como personas libres e iguales involucradas en la cooperación social durante toda una vida:

Los que tienen mayor responsabilidad y riqueza pueden controlar el curso de la legislación en su propio provecho (...) El valor de las libertades políticas para todos los ciudadanos, sea cual fuere su posición social o económica, debe ser aproximadamente igual, o al menos suficientemente igual en el sentido de que todo el mundo tenga una oportunidad equitativa de tener un cargo público e influir en el resultado de las decisiones políticas.

Rawls (2001: 40) introduce el concepto de equidad al señalar:

Debemos establecer un punto de vista desde el que pueda alcanzarse un acuerdo equitativo entre personas libres e iguales; mas este punto de vista debe quedar al margen 
de los rasgos y circunstancias particulares de la estructura básica existente y no ser distorsionado por ellos. En la posición original no se permite a las partes conocer sus posiciones sociales o las doctrinas comprensivas particulares de las personas a las que representan. Tampoco conocen la raza y el grupo étnico de las personas, ni su sexo o sus diversas dotaciones innatas tales como el vigor o la inteligencia. Expresamos metafóricamente estos límites a la información diciendo que las partes están bajo un velo de ignorancia.

Para Rawls, la posición original es entendida como un mecanismo de representación. En su obra, este autor se enfrenta al utilitarismo y a la visión de la justicia como bienestar de la mayoría, ya que convalida la minoría mayoritaria. Rawls se opone a que las mayorías impongan su voluntad y que las minorías sean aplastadas.

Hasta aquí se ve que la legitimidad del Derecho no radica en un ficticio consenso universal kanntiano o de mínimos rawlsiano, en la idea de que existe una norma no positiva que señala qué es Derecho legítimo o norma de reconocimiento hartiana, ni corresponde al modo marxista, pues no hallamos cuál es la clase obrera que presuntamente tendría que abanderar la emancipación social y política, ya que es esta misma la que precisamente, por medio de su voto, reivindica al ethos neoliberal dominante.

De otra parte, Alexy (2001: 103), al establecer los fundamentos que legitiman al Derecho, nos habla de "un consenso elaborado discursivamente que se mantiene controlado cuando se acepta el derecho del interlocutor a orientar su conducta sólo en principios que, después de suficiente reflexión, se juzguen correctos y en consecuencia válidos”.

Marcuse (1968: 115) manifiesta, en relación con la preservación de la legitimidad del Estado por parte del ethos económico, que:

los resultados de las votaciones populares modernas demuestran que los hombres, separados de la verdad posible, pueden ser inducidos a votar contra sí mismos. Mientras los individuos vean sus intereses sólo en el progreso dentro del orden dado, resulta fácil para un aparato totalitario controlar estas votaciones. El terror solo contribuye a reforzar el engaño en que se encuentran los gobernados. La invocación de estos intereses es falsa.

Para Michel Foucault (1994: 28), es interesante intentar la comprensión de nuestra sociedad mediante sus sistemas de exclusión, sus formas de rechazo, de negación, de lo que no se quiere, de sus límites, del sentimiento de obligación que incita a suprimir un determinado número de cosas, de personas, de procesos; por tanto, mediante lo que se deja oculto bajo el manto del olvido, en fin, desde el análisis de los sistemas de represión-eliminación propios de la sociedad.

En relación con la legitimidad democrática, Duncan Kenndy (2005: 104) plantea:

las normas y leyes vigentes, las escogió una gente que tenía el poder suficiente para optar conforme a su peculiar manera de entender la moral, la justicia y sus propios intereses. Considero además, que las normas y las leyes siguen en vigencia porque los grupos que han sido tratados injustamente, no han tenido la visión política, la energía y la fuerza bruta para cambiarlas.

De otra parte, Habermas (1989: 376), al aludir el funcionalismo sociológico de Weber, señala:

los procesos de racionalización social, buscan como punto de referencia la racionalidad sistémica: el saber susceptible de racionalización se expresa en la capacidad de autorregulación de sistemas sociales que para reproducirse han de adaptarse a entornos cambiantes. El comportamiento racional con arreglo a fines de los miembros del sistema pierde entonces su posición central para la problemática de la racionalidad; de ahora en adelante lo que interesa es la aportación funcional que cualquier estado o elemento hace a la solución de los problemas sistémicos.

Habermas (1989: 408), en su teoría de la acción comunicativa, expresa:

los fenómenos específicos de alienación de las sociedades modernas se explican porque ámbitos del mundo de la vida comunicativamente estructurados quedan crecientemente sometidos a los imperativos de sistemas autonomizados que, por su parte, se diferenciaron a través de los medios dinero y poder, y que representan un fragmento de "socialidad" exento de contenido normativo.

En la acción comunicativa, los agentes no se orientan por beneficio particular sino por el entendimiento,

Cuando se logra un entendimiento, conduce entre los participantes a un acuerdo. Un acuerdo comunicativamente alcanzado cumple no sólo las condiciones de un acuerdo fácticamente existente. Antes bien, el acuerdo sólo se produce bajo condiciones que remiten a una base racional. El acuerdo descansa sobre una convicción común (Habermas, 1989: 385). 
El argumento de consenso constituye un argumento central de la fundación habermasiana de un sistema de derechos. La legitimidad del Derecho se vincula así a la aceptación universal. Esto corresponde al principio del discurso mencionado para el cual normas de acción válidas, y en consecuencia legítimas, son las que todos los posibles afectados como participantes en discursos racionales pueden aceptar. Habermas denomina a esto la "génesis lógica de derechos" (Alexy, 2001: 114).

Habermas (1999: 123), al referirse al tema de inclusión sensible a las diferencias, manifiesta:

el problema de las minorías nacidas se plantea en las sociedades democráticas cuando la cultura mayoritaria políticamente dominante impone su forma de vida y con ello fracasa la igualdad de Derechos efectiva de ciudadanos con otra procedencia cultural. Esto tiene que ver con cuestiones políticas que afectan la auto compresión ética y la identidad de los ciudadanos. En esta materia las minorías no se pueden mayorizar sin más.

Sobre el multiculturalismo, Raz (1994), citado por Habermas (1999: 126), sostiene que "los miembros de todos los grupos culturales habrán de adquirir un lenguaje político y convenciones de conducta comunes para poder participar de modo efectivo en la competición por los recursos y la protección de grupo así como los intereses individuales en una arena política compartida".

\section{El factor económico como fundamento de legitimación del ordenamiento jurí- dico nacional}

En Colombia, la identificación del ethos cultural que identifica a los nacionales colombianos es tratado por el profesor De Zubiría Samper (1998: 50), quien señala:

\footnotetext{
Existen tres matrices que se yuxtaponen en nuestro comportamiento ético y cultural: elogiamos la existencia de normas legales, pero éstas no modifican nuestra conducta cotidiana; despreciamos y desconfiamos de todo lo que provenga de las instituciones; y desconectamos con demasiada facilidad y frecuencia las normas morales de las jurídicas y estas dos de las culturales (el colombiano puede vivir con normas culturales que se contradicen con sus propios principios morales).
}

Nieto Arteta (1971: 16), siguiendo a Kelsen, señala que el Derecho natural es un procedimiento teórico para defender determinados intereses económicos y políticos. Para él, el contenido esencial del ordenamiento estatal, no es otra cosa que intereses de grupo y de clase, que tratan de atrincherarse tras la teoría. La regulación de la vida social está unida a los intereses del hombre. Ningún hombre es indiferente ante la regulación de la vida social. Lo vinculan a ella sus propios intereses personales (económicos y culturales).

En este sentido se ve que pretender concebir la legitimidad del ordenamiento jurídico por fuera del entramado economía-fuerzas productivas no es posible, ya que nuestro contexto social nos enseña que la legitimidad del sistema jurídico nacional no se funda en concepciones abstractas y teóricas que se aparten de la realidad económico-política que rige a las sociedades.

El ordenamiento jurídico colombiano no radica en el consenso, por la imposibilidad de lograr un acuerdo entre las muchas eticidades disímiles, e incluso opuestas, que coexisten en nuestro Estado, sino que se halla en la voluntad del ethos del grupo vencedor en la competencia económica.

Mejía Quintana (2003) sostiene que no existió un consenso en la Asamblea Constituyente de 1991, dado que esta no fue representativa de la totalidad de "formas de vida" que se encuentran en Colombia y ve en ello el porqué. Para Mejía el acrecentamiento del conflicto armado es síntoma del inconformismo y la discriminación social y cultural que se han generado.

La regla de reconocimiento, la norma fundamental, el consenso o como queramos llamarlo, en el pueblo colombiano, la hallamos en la premisa: "es legítimo el ordenamiento jurídico que establezca el vencedor en la competencia económica del mercado", porque su ethos es capaz de imponerse a las demás eticidades y mantenerlas agazapadas conservando, no obstante, el orden público y la estabilidad económica. Esto se evidencia en nuestro país, cuando vemos cómo el narcotráfico es la actividad económica más fuerte, que se sirve de un brazo armado ilegal, tanto paramilitar como guerrilla, y de la forma tradicional de hacer política en Colombia, para acercarse y tener vínculos en los más elevados cargos de dirección del Estado.

De otro lado, vemos que la figura del Presidente de la República, quien debe representar la unidad o cohesión del pueblo, personifica realmente el ethos dominante. Es precisamente el presidente, el llamado a ser el guardián de la Constitución, quien propugna por reformarla o cambiarla, siempre que no traduzca, en mayor o menor medida, los intereses de su clase, su ethos económico. 
El tribunal constitucional tampoco defiende ese supuesto consenso constitucional, en la medida en que esta corporación es escogida por el Senado de la República -la más clara manifestación del ethos económico dominante- de sendas ternas que le presentan el Presidente de la República, la Corte Suprema de Justicia y el Consejo de Estado. En este proceso, el senado colombiano comparte la eticidad del ejecutivo la mayoría de las veces, porque ambos tienen la misma procedencia: son escogidos por votación popular, las cuales son manipuladas por el ethos económico dominante; cuando esto es así, el Senado optará por el candidato del ejecutivo como ocurre en la actualidad.

La capacidad de permeabilidad que tiene el ethos dominante (el económico) en la sociedad es tan vasta, que incluso llega a tener competencia en las esferas jurídicas, más exactamente en los fallos de la Corte Constitucional. El caso de la declaratoria de exequibilidad de la reforma a la ley laboral del año 2002, es el caso más flagrante de la superposición de los principios neoliberales por encima de los principios que propugna el Estado social de derecho.

En este tipo de situaciones se logra advertir que, por un lado, se encuentra la solución al problema de la pobreza en la incentivación a la empresa privada, si hay industria, hay empleo y hay salarios que le permiten al ciudadano tener una vida digna. Por tal razón, para los que comparten esta eticidad, no hay que invertir en lo social sino en la empresa y estimular la privatización.

Así, nos encontramos al borde del absolutismo, pues poco a poco se ha resquebrajado el sistema de frenos y contrapesos de todo el ordenamiento jurídico colombiano, ya que, al haberse instituido la figura de la reelección inmediata, el ejecutivo tiene la capacidad de elegir, veladamente, desde los magistrados de las altas cortes, el fiscal general de la Nación, la junta directiva del Banco de la República y hasta los representantes de los órganos de control, de manera tal que el ejecutivo controla y manipula todos los factores de poder, sin que exista una real separación de poderes. El poder se concentra en el ejecutivo, obrando una involución, un retroceso al concepto primigenio de poder público, donde no existe una tridivisión del poder, como lo plantea Montesquieu, y mucho menos los órganos de control.

\section{Discusión}

La legitimidad del ordenamiento jurídico colombiano no deviene del consenso social sino de la victoria de un ethos sobre otro en el plano económico. No obstante, al ser imposible que exista un acuerdo universal de la sociedad, debido a su pluralidad ética, esta se encuentra regida por un sistema normativo, que aunque no resuelve la totalidad de los conflictos, logra al menos asegurar el orden público. Nuestra sociedad ha reconocido el hecho de salir victorioso en la dura competencia del mercado como fundamento de legitimidad. De forma tal, que la legitimidad no tiene como eje a las mayorías o minorías éticas que se imponen unas sobre otras, sino el reconocimiento de aquel ethos que logra imponerse frente los otros.

La norma fundamental es el ethos económico dominante, que actualmente se encuentra plasmado en el texto constitucional en la parte que desarrolla los principios de la economía neoliberal; este es el punto de contacto entre el sistema político y el jurídico ya que es el ethos económico el que señala las políticas a asumir y estas, a su vez, son reflejadas en los fallos judiciales.

Entendida así, nuestra norma fundamental no es fruto de un consenso político universal sino de la victoria en la competencia del mercado de una determinada eticidad, de manera tal, que existen simultáneamente diversas eticidades que en su interacción generan tensiones que se evidencian en el perenne conflicto interno colombiano. En momentos en que el choque de eticidades se ha intensificado, deviene la inestabilidad política. Es aquí donde el ethos dominante, en cuyas manos se encuentra el poder político, se sirve del ius belli y la teoría schmittiana amigo-enemigo satanizando la oposición, tachando a los desobedientes del ordenamiento de enemigos y aplicando el axioma que señala que la democracia es para los amigos y para los enemigos todo el rigor de la ley, así se autorregula el sistema.

\section{BIBLIOGRAFÍA}

Adorno, T. (1969). Crítica, cultura y sociedad. Barcelona: Editorial Ariel.

Alchourron, C.E. y Buligyn, E. (1974). Análisis lógico y Derecho. Buenos Aires: Editorial Astrea.

Aristóteles, (1984). La política. España: Ediciones Orbis.

Aristóteles, (1985). Ética a Nicómaco (edición bilingüe de M. Araujo y J. Marías). Madrid: Centro de Estudios Constitucionales. 
Alexy, R. (2001). Teoría del discurso y derechos humanos. Serie de Teoría Jurídica y Filosofía del Derecho. Bogotá: Universidad Externado de Colombia.

Austín, J. (1885). Lectures on jurisprudence $\left(5 .^{a}\right.$ edición revisada y editada por R. Cambell y J. Murray). London.

Bloch, E. (1983). El ateísmo en el cristianismo. Madrid: Taurus Ediciones.

Bourdieu, P. (2002). La fuerza del Derecho. Bogotá: Ediciones Uniandes, Instituto Pensar y Siglo del Hombre.

Buchanan, J. (1996). Ética y progreso económico. Barcelona: Editorial Ariel.

Cortez, A. (2006). ¿Cuántos somos en realidad? Cali, Colombia: Corporación Editora Médica del Valle y Universidad del Valle.

De Zubiría, S. (1998). Filosofía de nuestro ethos cultural. Revista de Estudios Sociales, 1, agosto.

Díaz y Díaz, M. (1998). Derecho y orden. Ensayos para el análisis realista de los fenómenos jurídicos. México: Distribuciones Fontamara.

Díaz, E. (1998). Ética contra política. México: Editorial Distribuciones Fontamara.

Fariñas, Dulce, M.J. (1991). La sociología del Derecho de Max Weber. Editorial Civitas. Madrid: 261-274.

Farrell, D.M. (1997). Utilitarismo, liberalismo y democracia. Biblioteca de Ética, Filosofía del Derecho y Política. México: Ediciones Fontamara.

Foucault, M. (1994). Estrategias de poder. Barcelona: Editorial Paidós.

Gil, N.A. (Comp.). (2006). Filosofía del Derecho y Filosofía social. Bogotá: Grupo Editorial Ibáñez.

Gurvitch, G. (2001). Elementos de Sociología jurídica. Granada, España: Editorial Comares.

Habermas, J. (1989). Teoría de la acción comunicativa: Complementos y elementos previos (traducción de $\mathrm{M}$. Jiménez Redondo). Madrid: Ediciones Cátedra.
Habermas, J. (1999). La inclusión del otro. Estudios de teoría política. Barcelona: Ediciones Paidós Ibérica.

Hart, H. (1963). El concepto de Derecho (2. ${ }^{a}$ ed., traducción de G. Carrió). Buenos Aires: Editorial Abeledo Perrot.

Hegel, F.G.W. (1980). La filosofía del Derecho. México: Fondo de Cultura Económica.

Hobbes, T. (1989). Leviatán. La materia, forma y poder de un Estado eclesiástico y civil. Madrid: Alianza.

Hobbes, T. (1984). Elementos de Derecho material y político (2. ${ }^{a}$ reimpresión). México: Fondo de Cultura Económica.

Kant, I. (2003). Fundamentación de la metafísica de las costumbres. Argentina: El Cid.

Kant, I. (1958). Idea de una historia universal desde un punto de vista cosmopolita. En Filosofía de la historia. Buenos Aires: Editorial Nova.

Kaufmann, M. (1993). Derecho sin reglas (2. a ed.). Munich: Editorial Alfa.

Kelsen, H. (1994). La norma fundamental. En Teoría pura del Derecho. Buenos Aires: Editorial Porrúa.

Kelsen, H. (1969). Teoría general del Derecho y del Estado ( $3^{\mathrm{a}}$ ed.). México: Editorial Textos Universitarios y Universidad Nacional Autónoma de México.

Kennedy, D. (2005). Libertad y restricción en la decisión judicial. El debate con la teoría crítica del Derecho. Bogotá: Siglo del Hombre Editores.

Locke, J. (1991). Dos ensayos sobre el gobierno civil. Madrid: Espasa Calpe.

López, Medina, D.E. (2004). Teoría impura del Derecho. Bogotá. Legis.

Lorca, Navarrete, J.F. (1982). Fundamentos filosóficos del Derecho. Madrid: Ediciones Pirámide.

Luhmann, N. (1997). Organización y decisión. Autopoiesis y entendimiento comunicativo. México: Universidad Iberoamericana. Editorial Anthropos. 
Macintyre, A. (2001). Animales racionales e independientes. Barcelona: Paidós.

Marcuse, H. (1968). Cultura y sociedad. Buenos Aires: Editorial Sur.

Mejía Quintana, O. (2003). El origen constituyente de la crisis política en Colombia. En A. Mason y L.J. Orjuela (eds.). La crisis política colombiana. Bogotá: Universidad de los Andes.

Mejía, Quintana, O. (2006a). Elementos para una reconstrucción del estatuto epistemológico de la filosofía del Derecho. Universidad Autónoma de Nuevo León. Humanitas, 33.

Mejía, Quintana, O. (2006b). La norma básica como problema iusfilosófico. Tensiones y aporías del positivismo y las apuestas pospositivistas de superación. En: N.A. Gil (comp.). Filosofía del Derecho y Filosofía Social (Memorias). Bogotá: Grupo Editorial Ibáñez.

Mejía, Quintana, O. (1995). El Derecho, liturgia del procedimentalismo (manuscrito).

Nieto, Arteta, L.E. (1971). La interpretación de las normas jurídicas. Bogotá: Universidad Nacional de Colombia.

Nozick, R. (1990). Anarquía, Estado y utopía. México: Fondo de Cultura económica.

Raz, J. (1994). Multiculturalismo: Una perspectiva liberal. Dissent (Winter).

Rawls, J. (1990). Sobre las libertades. Barcelona: Ediciones Paidós Ibérica.

Rawls, J. (2001). La justicia como equidad. Una reformulación. Barcelona-Buenos Aires-México: Editorial Paidós.

Rousseau, J. (1969). El contrato social. En Obras completas, 3. París: Editorial Bernard Gagnebin y Marcel Raymond.

Ruiz, M.A. (2002). Una filosofía del Derecho en modelos históricos. De la antigüedad a los inicios del constitucionalismo. Madrid: Trotta.

Schmitt, C. (1971). Legalidad y legitimidad. Madrid: Aguilar.
Schmitt, C. (1991). El concepto de lo político. Madrid: Alianza.

Taylor, C. (2002). La ética de la autenticidad. BarcelonaBuenos Aires-México: Paidós.

Teubner, G. (2002). El Derecho como sujeto epistemológico: hacia una epistemología constructivista del Derecho (Traducción de C. Gómez y J. Díez). Doxa. Cuadernos de Filosofía del Derecho.

Turegano, Mansilla, I. (2001). Derecho y moral en John Austin. Madrid: Centro de Estudios Políticos y Constitucionales.

Twining, W. (2005). Derecho y globalización. Bogotá: Siglo del Hombre Editores, Universidad de los Andes, Pontificia Universidad Javeriana e Instituto Pensar.

Weber, M. (1964). Economía y sociedad (2. ${ }^{\text {a }}$ ed.). México: Fondo de Cultura Económica. 